\title{
Battery Charger for Hybrid Locomotive
}

\author{
Jaroslav Novák ${ }^{1)}$, Ondřej Sadílek ${ }^{2)}$ and Zdeněk Mašek ${ }^{3)}$ \\ 1) University of Pardubice, Faculty of Transport Engineering, Pardubice, Czech Republic, \\ e-mail: jaroslav.novak@upce.cz \\ 2) University of Pardubice, Faculty of Transport Engineering, Pardubice, Czech Republic, \\ e-mail:ondrej.sadilek@upce.cz \\ 3) University of Pardubice, Faculty of Transport Engineering, Pardubice, Czech Republic, \\ e-mail: zdenek.masek@upce.cz.
}

\begin{abstract}
The paper introduces the concept and functionality of the battery charger - pulse rectifier control system for hybrid shunting locomotive. The locomotive producer is the company $\mathrm{CZ}$ LOKO a.s. The pulse rectifier operates in several modes including modes with charging of the traction battery from the alternator or from the distribution net, emergency mode or test modes. The paper presents the integration of the pulse rectifier into the context of the hybrid drive and the results of partial tests of drive control.
\end{abstract}

Keywords - battery charger, locomotive, hybrid drive, pulse rectifier, control system.

\section{INTRODUCTION}

There is great potential in rail transport for the use of vehicles with battery power in shunting service. This mode of operation is very inefficient for a diesel vehicle. It is disadvantage that during shunting alternate frequent starts with repeated stops, not negligible are the time intervals when the vehicle is stationary and the internal combustion engine is idling. The average power taken from the dieselelectric shunting locomotive's drive unit is about $10 \%$ of the internal combustion engine's rated power. The relatively powerful internal combustion engine is thus operated with a high frequency of transient states with very unfavorable specific fuel consumption and disproportionate emissions of pollutants.

Hybrid shunting locomotives of the modern concept have been developed worldwide in several types, such as Toshiba HD 300 four-axle locomotives, four-axle BR 203H with Alsthom electrical equipment or Canadian Railpower GG20B four-axle locomotive. More detailed information can be found in [1], [2].

The prototype development of a new two-axle shunting locomotive produced by CZ LOKO a.s. is supported by the TRIO program of the Ministry of Industry and Trade. In addition to CZ LOKO a.s. MSV ELEKTRONIKA and University of Pardubice, Faculty of Transport Engineering are involved in the development of the locomotive. Many other entities as subcontractors are also involved in the development. The University of Pardubice is primarily responsible for conceptual work, including simulation calculations, design of control algorithms for battery technologies and cooperates in the commissioning and testing of hybrid drives.

\section{CONCEPTION OF LOCOMOTIVE AND TRACTION CHAIN}

The prototype of the developed hybrid locomotive is suitable for universal shunting and siding services.
Important parameters are summarized in the table below.

TABLE I.

IMPORTANT PARAMETERS OF HYBRID LOCOMOTIVE

\begin{tabular}{|c|l|}
\hline Arrangement of wheelsets & Bo \\
\hline Total traction power & $350 \mathrm{~kW}$ \\
\hline Power of combustion engine & $129 \mathrm{~kW}$ \\
\hline Maximal speed & $80 \mathrm{~km} / \mathrm{h}$ \\
\hline Weight & $44 \mathrm{t}$ \\
\hline Capacity of traction battery & $\begin{array}{l}120 \text { až } 160 \mathrm{kWh} \text { (in dependence } \\
\text { of operations character) }\end{array}$ \\
\hline Operating temperature range & $-40^{\circ} \mathrm{C}$ to $+50^{\circ} \mathrm{C}$ \\
\hline
\end{tabular}

Total outside design is obvious from the picture Fig. 1.

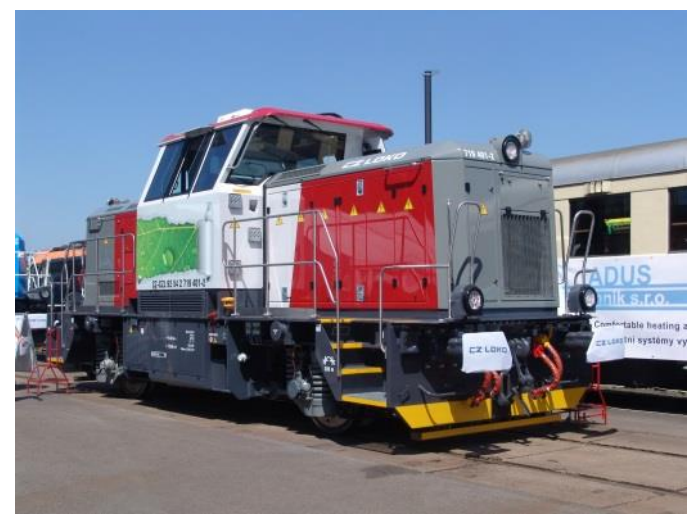

Fig. 1. Hybrid locomotive from CZ LOKO a.s. production [4].

The overall structure of the locomotive traction chain is evident from the block diagram in Fig. 2. This is a series structure of a hybrid drive where the central node of the traction chain is a DC link to which a traction accumulator battery is connected in parallel. A pair of traction inverters for traction asynchronous motors is supplied from the DC link. Unified traction motors $2 \times 366 \mathrm{~kW}$ will not be fully utilized in this application because the total traction output of the locomotive is $350 \mathrm{~kW}$. The auxiliary consumption circuits of the locomotive are further supplied from the DC link. 


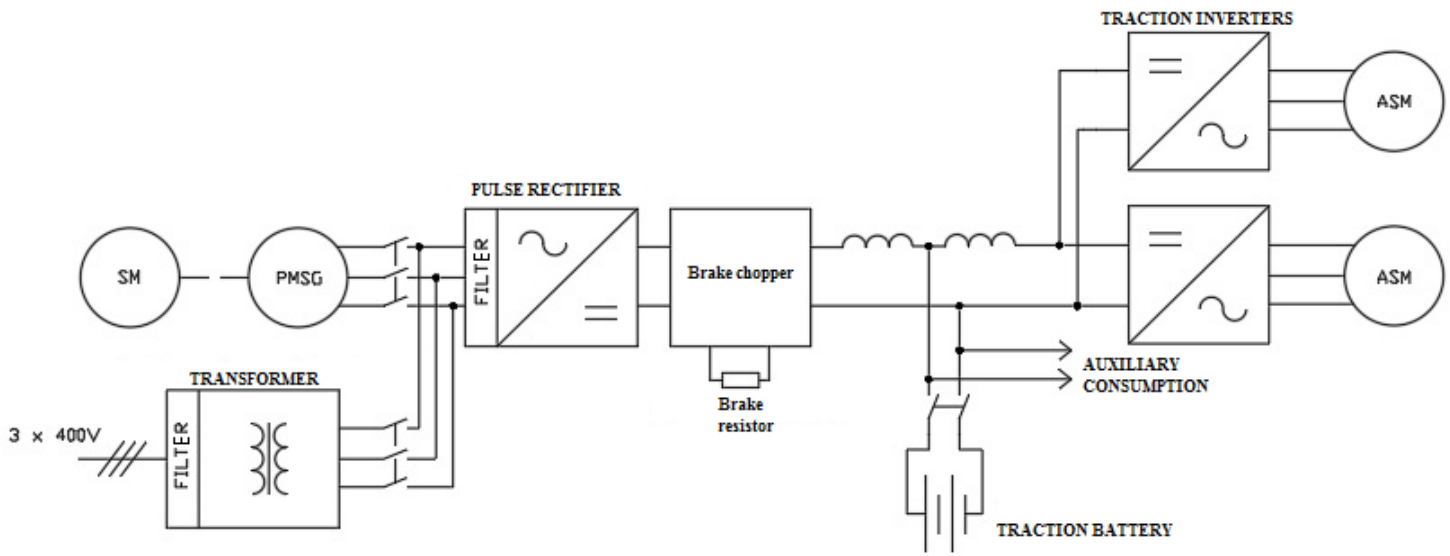

Fig. 2. Block diagram of hybrid locomotive traction chain.

When the traction battery needs to be charged, the internal combustion engine is started, which drives a permanent magnet synchronous generator supplying the DC link via the pulse rectifier with a charging current. In addition to the generator, it is possible to charge the traction battery from the mains connection with reduced power. In this case, the pulse rectifier works as a mains charger.

A braking resistor with switching transistor is also included in the DC link. The locomotive's electrodynamic brake control strategy is designed so that maximum braking power is always used to charge the battery.

The concept of a vehicle with full battery power supply was completed with the addition of a battery charging source - it means an internal combustion engine with a generator, a converter and with a corresponding dimensioning of the traction battery. The reasons for choosing this solution are mainly the reduction of the output of the internal combustion engine and generator, the possibility of full accumulator operation with the elimination of the idling of the internal combustion engine, the possibility of emission-free operation, efficient regenerative braking and operation of the internal combustion engine with minimal specific fuel consumption.

\section{FUnCTION OF PULSE RECTIFIER}

The main actuator of the hybrid locomotive's charging system is a pulse rectifier consisting of a three-phase transistor bridge. The pulse rectifier is solved in the progressive technology of $\mathrm{SiC}$ power switching elements and operates with a switching frequency of $30 \mathrm{kHz}$. A sinusoidal filter is connected to the AC input terminals of the rectifier to reduce the undesirable effects associated with the fast switching of $\mathrm{SiC}$ components. The pulse rectifier operation modes are as follows:

- Charging mode of the traction battery from an alternator driven by an internal combustion engine.

- Charging mode of the traction battery from main connection $3 \times 400 \mathrm{~V} 50 \mathrm{~Hz}$, typical $32 \mathrm{~A}$.

- Emergency mode - a mode in which the traction battery is shut down and the locomotive can be operated with limited traction power.
Activation of the individual modes of the pulse rectifier in its regulator is performed on the basis of commands that are transmitted from the master control system of the locomotive via CAN bus. The pulse rectifier controller transmits information of the actual statuses and progress of significant control quantities via this bus to the master control system.

The development of SW for the pulse rectifier regulator is the Faculty of Transport Engineering of the University of Pardubice at the level of analysis and design of control algorithms. The Czech Technical University in Prague, the Faculty of Mechanical Engineering participates as a subcontractor at the implementation level. The sbRIO 9607 system with the NI 9684 option card for power converter control is used as a controller. The sbRIO controller is programmed in the LabVIEW graphical environment.

\section{REGULATION ALGORITHMS}

During charging from a permanent magnet synchronous generator, the cascade control structure of Fig. 3 is used.

The rectifier output current $\mathrm{I}_{\mathrm{DC}}$ is controlled at the superior control level. The output of the superior control level is the generator torque desired value, assuming operation at an optimal constant engine speed of $1800 \mathrm{rpm}$. A standard vector structure for synchronous machines is used for regulating the generator torque, which is described, for example, in [3].

The desired value of the $I_{D C}$ current is entered via the CAN line into the inverter controller by the locomotive master control system and its value is based on the overall operating mode of the locomotive and is limited by the instantaneous state, especially temperature and capacity. The primary information of limiting is provided to master control system from battery management system.

In order to improve the dynamic properties of the $I_{D C}$ current control, it is configurable to use the forward control principle, where the torque setpoint of the generator $\mathrm{M}$ entering the vector control is determined as the sum of the $\mathrm{I}_{\mathrm{DC}}$ controller output according to Fig. 3. The principle of calculating the desired torque $\mathrm{M}^{*}$ can be described by the relation where $\mathrm{M}_{\mathrm{DV}}$ is the desired torque of the generator determined by the calculation:

$$
M^{*}=\text { Out } \operatorname{Re} g I_{D C}+M_{D V}
$$




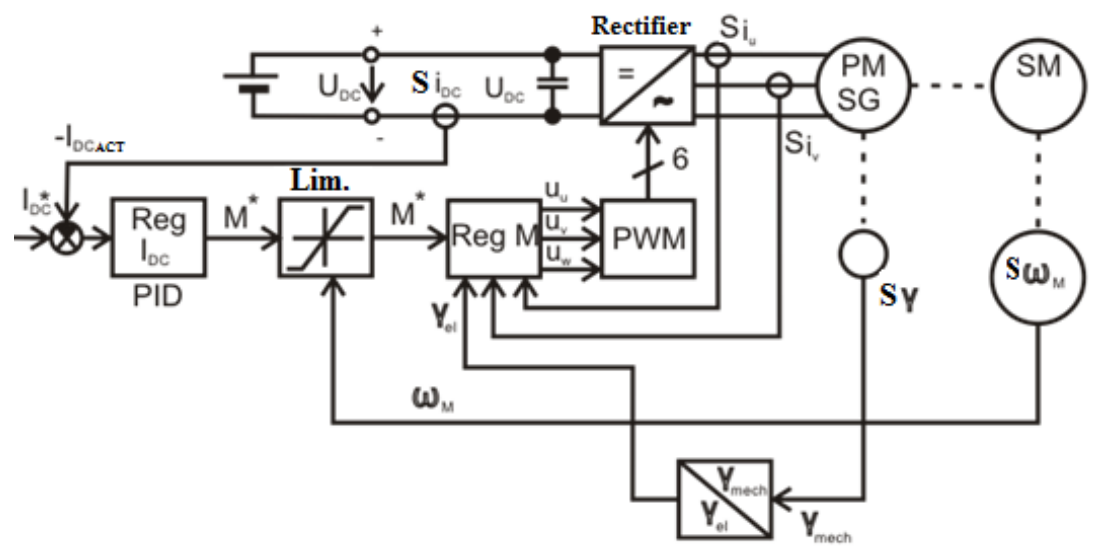

Fig. 3. Regulation structure for charging battery from generator.

$$
M_{D V}=\frac{U_{D C} \cdot I_{D C}}{\omega_{\text {mech }}}
$$

In the equation (2) $\mathrm{U}_{\mathrm{DC}}$ marks the immediate value of voltage measured by the sensor on the DC side of the inverter, $\mathrm{I}_{\mathrm{DC}} *$ immediate desired value of the current on the DC side of the inverter, $\omega_{\text {mech }}$ immediate value of angular speed of the generator measured by sensor. In the block diagram of Fig. 3, the symbol S marks the sensor of specific variable. This calculation awaits equality of mechanical input power on the generator shaft and output power of the pulse rectifier. Both values are close, but do not take into account the power loses in the generator and pulse rectifier. In particular, this inaccuracy corrects the $I_{D C}$ feedback controller.

During charging the traction battery from the $3 \times 400 \mathrm{~V}$ mains connection, the charging power is limited to approximately $20 \mathrm{~kW}$. This limitation is due to the maximum current of the mains connection of $32 \mathrm{~A}$. During charging from the mains connection, the charging power passes through the input isolation transformer, the sine filter and the pulse rectifier. The control structure with superior control of the DC charging current $\mathrm{I}_{\mathrm{DC}}$ is based on Fig. 3, but differentiate with the subordinate control. In order to maximize the unification of the subordinate control algorithms in the generator and mains charging mode, regulation of the pulse rectifier powered from the mains connection was developed, which represents a direct analogy to the torque control structure of a permanent magnet synchronous machine. The control structure analogy is based on the analogy between the variables in operation with the synchronous generator and the mains connection:

- The induced voltage $\mathrm{u}_{\mathrm{i}}$ of the generator corresponds to the terminal secondary voltage of the isolation transformer $\mathrm{u}_{\mathrm{s}}$.

- The internal inductance and resistance of the synchronous machine $\mathrm{L}$ and $\mathrm{R}$ correspond to the $\mathrm{L}_{\mathrm{SIN}}$ inductance and the $\mathrm{R}_{\mathrm{SIN}}$ resistance of the sinusoidal filter connected between the isolation transformer and the pulse rectifier.

- The transformation angle $\gamma$ for the Park Transformation calculation is determined by measuring or calculating the angular rotation of the rotor in the case of a synchronous machine. In the case of mains supply, this angle shall be determined from the measured waveforms of the secondary terminal voltages of the isolation transformer.

The phasor diagram in Fig. 4 illustrates the situation in controlling with a zero phase shift pulse rectifier between the phase voltage on the transformer secondary winding and the current drawn by the pulse rectifier at that phase. The figure shows the 1st harmonic component of current and voltage.

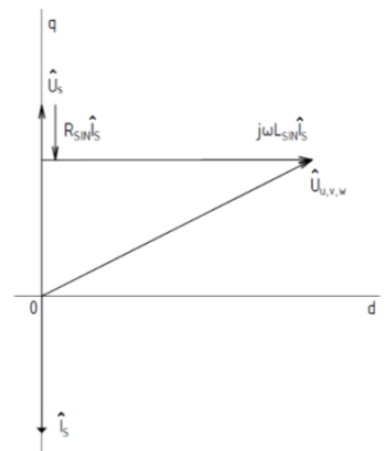

Fig. 4. Phasor diagram of the circuit with pulse rectifier and sine filter in the case of mains supply $3 \times 400 \mathrm{~V}$.

It is clear from the phasor diagram that the phase voltage phasor on the secondary winding of the transformer $U_{S}$ is laid on the q-axis. The q-axis thus determines the direction of the active component of the current $i_{P}$ taken by the pulse rectifier. In case the power factor of the pulse rectifier in conjunction with the sine filter equals 1 , the phasor $\mathrm{I}_{\mathrm{S}}$ of the current drawn from the mains in the direction of the q axis. The voltage phase $U_{U}, v, w$ represents the first harmonic component of the terminal voltage of the pulse rectifier. When calculating the Park transformation in the control structure, the transformation angle $\gamma=0^{\circ}$ is given when the transformer phase $\mathrm{U}$ voltage is zero and changes from positive to negative polarity. Since the coupled secondary voltages are measured to synchronize the drive control, an angle $\gamma$ with a phase shift of $30^{\circ}$ to the zero coupled voltage $\mathrm{u}_{\mathrm{UV}}$ is determined. The instantaneous value of the transformation angle $\gamma=\omega \mathrm{t}$.

The control structure of the pulse rectifier when powered from the $3 \times 400 \mathrm{~V}$ mains is analogous to the structure of the synchronous machine torque control according to [3]. For mains power, the following specifics are given:

- Regulation of the phasor current component $i_{q}$ of the synchronous machine corresponds to regulation of the mains active current 
component $I_{P}$, the component $i_{d}$ corresponds to the reactive current component $\mathrm{i}_{\mathrm{Q}}$, this component is controlled to zero.

- The active current component $i_{P}$ of the mains is an action variable in terms of the control loop of the DC output current of the pulse rectifier IDC.

As with the synchronous machine regulation, the actual feedback values of the current components $i_{P}$ and $i_{Q}$ are calculated from the measured phase current values $i_{U}, i_{V}, i_{W}$ according to the formulas:

$$
\begin{aligned}
& i_{Q}=\frac{2}{3}\left(\mathrm{i}_{U} \cdot \cos \gamma+i_{V} \cdot \cos \left(\gamma-\frac{2 \cdot \pi}{3}\right)+i_{W} \cdot \cos \left(\gamma+\frac{2 \cdot \pi}{3}\right)\right) \\
& i_{P}=\frac{2}{3}\left(-i_{U} \cdot \sin \gamma-i_{V} \cdot \sin \left(\gamma-\frac{2 \cdot \pi}{3}\right)-i_{W} \cdot \sin \left(\gamma+\frac{2 \cdot \pi}{3}\right)\right)
\end{aligned}
$$

The current phasor drawn from the mains is given by formula:

$$
\hat{I}_{S}=i_{Q}+j \cdot i_{P}
$$

Similar to the synchronous machine's control structure, the current components $\mathrm{i}_{\mathrm{P}}$ and $\mathrm{i}_{\mathrm{Q}}$ are regulated in two parallel PS controllers and similar to the synchronous machine is it possible to use the block of decoupling in the case of mains supplying which makes predictive calculation of induced voltage. In the case of mains supplying respects existence of internal mains voltage $\mathrm{u}_{\mathrm{S}}$, whose phasor lies in the q-axis of coordinate system.

In the case of mains, the resulting value of the modulated voltage in the q-axis is determined as the sum of the output of the q-axis current regulator and the phasor voltage module $U_{S}$. The instantaneous voltage values $u_{S}$ of the secondary windings of the isolation transformer (internal mains voltage) are measured by the synchronization transformers. This procedure improves the control dynamics. The required modulated voltage of the pulse rectifier in the q-axis is thus determined from:

$$
u_{q}=\text { Out } \operatorname{Re} g i_{q}+\left|U_{S}\right|
$$

After the calculation of the voltage components $u_{d}$ and $u_{q}$ follows the inverse Park transform to phase voltages as input for PWM:

$$
\begin{gathered}
u_{U}=u_{d} \cdot \cos \gamma-u_{q} \cdot \sin \gamma \\
u_{V}=u_{d} \cdot \cos \left(\gamma-\frac{2 \cdot \pi}{3}\right)-u_{q} \cdot \sin \left(\gamma-\frac{2 \cdot \pi}{3}\right) \\
u_{W}=u_{d} \cdot \cos \left(\gamma+\frac{2 \cdot \pi}{3}\right)-u_{q} \cdot \sin \left(\gamma+\frac{2 \cdot \pi}{3}\right)
\end{gathered}
$$

The described control structure of the pulse rectifier with active $i_{P}$ control and reactive $i_{Q}$ component of the $I_{S}$ current phasor was successfully tested in the first half of 2019. Figure 5 shows the measured waveforms of the pulse rectifier at the sine filter input. A zero phase shift of both waveforms corresponding to regulation to $\mathrm{i}_{\mathrm{Q}}=0$ is evident. The tests were performed in a laboratory on a reduced physical model.

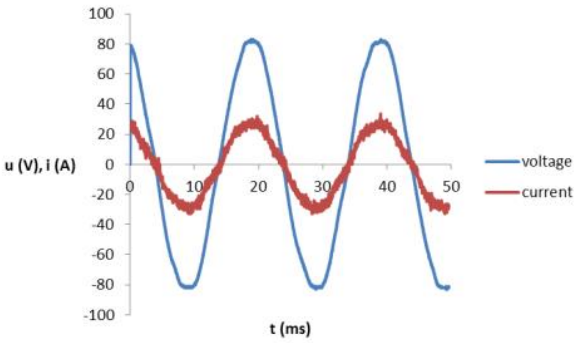

Fig. 5. Voltage and current waveforms at the rectifier sinusoidal filter input.

Figure 6 shows the response of the control loop of the current component $i_{p}$ at a step change of the desired value.

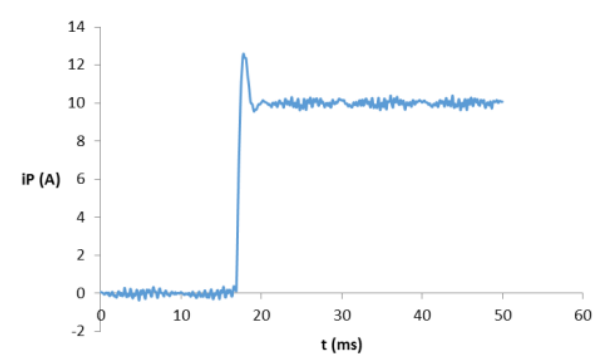

Fig. 6. Response of the current component of the current $i_{P}$ to the step change of the desired value.

The last control structure implemented in the pulse inverter controller is the $\mathrm{U}_{\mathrm{DC}}$ traction bus voltage control when the battery is disconnected. The structure in this control mode is the same as in Fig. 3, the $U_{D C}$ voltage regulator is implemented instead of the $I_{D C}$ current regulator.

\section{CONCLUSIONS}

The described method of pulse rectifier control was in the first half of 2019 tested in laboratory conditions on a reduced physical model, in the second half of 2019 the control SW is revived on a hybrid locomotive. In addition to reliable SW functionality, locomotive is required to be compatible with EN 50128 and meet the homologation requirements.

\section{ACKNOWLEDGMENT}

This work is supported by the Ministry of Industry and Trade grant TRIO FV 10724 Hybrid locomotive and energy electronical optimization of operation.

\section{REFERENCES}

[1] Y. Taguchi, S. Kadowaki, T. Nakamura, M. Miki, K. Hatakeda, and Y. Arita, "Development of a Traction Circuit for Battery-powered and AC-fed Dual Source EMU and Running Test Evaluation of the On-board Battery Performance," Quarterly Report of RTRI. Railway Technical Research Institute, 2015, 2015(56), 98-104. ISSN 1880 1765. https://doi.org/10.2219/rtriqr.56.98

[2] H. Girard, J. Oostra, and J. Neubauer, "Hybrid shunter locomotive," URL: //www.railway-research.org/IMG/pdf/r.2.2.3.1.pdf

[3] R. Doleček, J. Novák, and O.Černý, "Traction Permanent Magnet Synchronous Motor Torque Control with Flux Weakening," Radioengineering, 4/2009 VUT Brno, ISSN 1210-2512

[4] Technical documentation CZ LOKO

[5] Technical documentation National Instruments 